J. Lake Sci. (湖泊科学), 2012, 24(1): 17-26

http: //www. jlakes. org. E-mail : jlakes@niglas.ac.cn

(C) 2012 by Journal of Lake Sciences

\title{
环境规制对无锡市制造业结构优化与绩效的影响”
}

\author{
高 爽 ${ }^{1,2}$,魏也华 ${ }^{3}$, 陈 雯 $^{1}$ \\ ( 1 : 中国科学院南京地理与湖泊研究所, 南京 210008) \\ (2: 中国科学院研究生院, 北京 100049) \\ (3: 犹他大学地理系及公共与国际事务研究院, 盐湖城 84112-9155)
}

\begin{abstract}
摘 要: 环境规制已成为促进区域发展方式转变和经济可持续发展的重要驱动力. 本文以无锡市太湖水危机事件为例, 首先对水危机前后的环境规制政策和手段进行对比分析,其次结合现有理论研究,总结了环境规制对制造业产业结构优 化和绩效影响的理论框架,最后在对环境规制强度进行定量评估和对影响产业绩效各要素分析的基础上对理论框架进 行验证. 环境规制强度的评价结果表明,水危机事件后,环境规制强度显著增加,政府、技术、市场及社会工具的环境规制 强度均值在 2007-2009 年期间比 2001-2006 年期间分别增加了 2.2、1.0、2.6、0.7 倍,政府在加强行政管理的同时开始 积极探索市场化治理的工具,但以政府规制为主的治理模式仍然没有改变. 回归结果进一步表明环境规制通过影响企业 准人和提高技术效率, 实现产业结构的优化和生产效率的提高, 抵消了环境规制对生产成本增加而产生的消极作用,但 是创新仍没有成为产业绩效增加的最主要动力. 本研究对探讨经济和环境可持续发展模式以及环境规制手段的合理运 用具有重要的理论借鉴意义.
\end{abstract}

关键词: 太湖水危机; 环境规制; 制造业; 结构优化;产业绩效

\section{Effects of environmental regulation on the structure optimization and performance of man- ufacturing industry in Wuxi City}

\author{
GAO Shuang ${ }^{1,2}$, WEI Yehua Dennis ${ }^{3}$ \& CHEN Wen ${ }^{1}$ \\ (1: Nanjing Institute of Geography and Limnology, Chinese Academy of Sciences, Nanjing 210008, P. R. China) \\ (2: Graduate University of Chinese Academy of Sciences, Beijing 100049, P. R. China) \\ (3: Development of Geography and IPIA, University of Utah, Salt Lake City, Utah 84112-9155, USA)
}

\begin{abstract}
Environmental regulation has become one of the most important driving forces underlying sustainable development and the transformation of the pattern of economic development. The water pollution incident in Lake Taihu(2007), called Lake Taihu Water Crisis, has provided a typical study case to reveal the relationship between environmental regulation and economic development. First, through the case study of Lake Taihu Water Crisis, this study compared the approaches and policies of environmental regulation before and after the Lake Taihu Water Crisis. Second, this study summarized the existing literature and developed a new theoretical framework focusing on the impacts of environmental regulation on the optimization and performance of manufacturing industries. Finally, such a new framework was validated based on a quantitative assessment of the relative strengths of environmental regulation policies and an analysis of factors affecting industrial performance. The quantitative assessment of the strengths of environmental regulation policies showed that, after Lake Taihu Water Crisis, during 2007 - 2009, the environmental regulation has been gradually stronger. The average strengths of government regulation, technological regulation, marketing regulation and social regulation during 2007 and 2009 increased by 2.2,1.0,2.6, 0.7 times than the average strengths during $2001-2006$. The government not only used administrative commands (government regulation), but also tried to employ market-based regulation approaches on pollution control. However, the environmental regulation is still focused on the governmental regulation approach which has
\end{abstract}

* 中国科学院知识创新工程重要方向性项目 (KZCX2-YW-339) 和教育部人文社会科学重点研究基地重大项目 (11JJDZH005) 联合资助. 2011-06-23 收稿;2011-09-22 收修改稿. 高爽,女, 1984 年生,博士研究生; E-mail: gaoshuangwjc@163.com. 
not been changed. Regression results showed that the environmental regulation manifested by the constrains of enterprises' entering in pollution sectors and the encouragement of high-efficiency technologies, has resulted in the optimization of manufacturing industries and the productivity improvement in Wuxi, which also countered the negative impact of rising production costs brought by regulation. However, innovation is still not the main driving forces of industrial performance enhancement. This paper contributes to our understanding of the theories concerning the pattern of sustainable economic and environment-friendly development and the applicability of different environmental regulation approaches.

Keywords: Lake Taihu Water Crisis; environmental regulation; manufacturing industry; structure optimization; industrial performance

无锡市是太湖流域工业化和城市化快速发展的中心城市, 在工业化和城市化过程中, 由于经济增长远 远快于污染治理能力和水平的增长 ${ }^{[1]}$, 使得环境质量持续恶化, 不仅严重损害了城市和区域环境, 也日益引 起了社会不满,特别是 2007 年的太湖水危机事件将无锡推到了社会與论的风口浪尖. 因此,地方政府通过 制定相应的政策与措施、运用行政和市场工具等一系列环境规制手段,对厂商及其他造成环境污染的经济 活动进行调节, 尽可能地降低环境污染带来的外部不经济性, 以实现经济环境可持续发展的目标 ${ }^{[2]}$. 由此可 见, 无锡市作为我国工业化先发地区率先出现了环境问题, 制造业发展受环境规制影响的外在表现亦相对 明显,政府的各类环境规制政策对区域发展方式转变和可持续发展的影响日益显著. 自 2007 年无锡市工业 废水排放量开始呈现持续显著下降态势, 太湖流域的五里湖和梅梁湾以及市域主要河道水质也由劣 $\mathrm{V}$ 类水 质逐渐提高到 IV 类或 III 类水质, 可见, 环境规制措施的环境效益十分明显 ${ }^{\mathbb{1}}$. 然而, 太湖水危机前后环境规制 强度、构成及其持续性如何,环境规制的经济绩效如何,目前尚不清楚.

关于环境规制对经济发展的影响, 国内外学者做了较为系统的理论和实证研究, 主要形成以下三种观 点. 1970s 到 1980s 末期, 新古典经济学家认为, 环境规制要求企业支付一定的污染治理费用, 使得生产成本 增加, 此外, 还可能会挤占企业其他生产性、盈利性投资, 从而导致产出和利润的下降, 因此, 环境保护与经 济增长目标构成两难,一个目标的实现必定会损害另一个目标. 如 Christainsen 等通过建立环境规制与劳动 生产率的计量模型, 得出规制强度增加 1\%, 劳动生产率下降 $0.27 \%$ 的结论 ${ }^{[3]}$. Gray 等通过对美国 19791990 年 116 家纸浆和造纸厂的实证研究结果表明, 较高污染治理成本会显著降低企业的生产率水平, 具体 的降低水平受企业技术水平和企业规模的影响 ${ }^{[4]}$. 而到 $1990 \mathrm{~s}$ 初期, Porter 等对此假设提出挑战, 他认为环 境保护能提高效率并推动技术进步, 进而刺激经济增长 ${ }^{[5]}$. “波特假说” 提出后, 环境规制与技术创新、产业 绩效的关系, 引起了人们极大的兴趣, 也引发了大量相关的实证研究. Hamamoto 以日本制造业数据进行研 究, 认为环境规制的压力能够刺激创新活动, 从而对全要素生产率具有显著的正向推动作用 ${ }^{[6]}$. Kronvang 等 通过丹麦地下水污染事件后环境政策及其效果的评估表明, 政府部门针对地下水中 $N$ 、P 的削减政策以及积 极有效的实施保障机制对区域水环境有显著的改善效应, 并有效地引导了地区经济和相关产业的发展 ${ }^{[7]}$. 许冬兰等分析了在 1998-2005 年期间环境规制对中国东、中、西部地区工业的技术效率影响,结果表明环境 治理投人的增加明显地提高了中国工业技术效率 ${ }^{[8]}$. 从 $1990 \mathrm{~s}$ 中后期至今, 学者们试图更加全面、系统地分 析环境规制对产业绩效的影响, 认为环境规制对产业绩效的影响有多种效应, 并且要受到产业的状况和特 点、环境规制政策的质量等众多因素的影响. 如 Boyd 等对 1988-1992 年美国纸浆和造纸业环境规制对生产 率的影响进行了分析, 得出既存在产出增加与污染同时存在的情况, 也存在由于规制导致生产率降低的现 象 ${ }^{[9]}$. 解严通过检验环境治理投人对工业技术效率、技术进步和生产率增长的影响, 得出增加治污投资和减 少工业 $\mathrm{SO}_{2}$ 排放对工业生产率没有明显的影响, 这是由它们对生产率的两个组成部分的影响相抵消 所致 ${ }^{[10]}$.

以上的研究多限于对环境投人或者治理效果与产业绩效之间的影响关系进行定量分析, 或主要利用环 境治理来代替环境规制作为变量对经济或者企业效益进行测度, 而实际上较少从环境规制相关的各项政策 本身研究其对产业结构优化及其绩效的影响机制和作用机理. 此外, 对于此类研究的地域空间代表性不够

(1) 环境数据来源于《无锡市环境统计年报》(2001-2009). 
宽泛,多集中于大、中尺度地理范围的研究,而对于市域等小尺度的研究较为少见. 本研究在提出关于环境 规制对产业结构和绩效影响的理论假设基础上, 以无锡市为案例地区, 从实证角度研究环境规制强度的变 化及其对产业结构优化与绩效影响的过程及机制, 以期揭示环境突发事件对于区域产业发展的影响,为发 达地区经济与环境协调发展的实践提供理论借鉴,丰富和发展经济与环境协调发展的理论.

\section{1 环境规制对制造业产业绩效影响的理论框架及分析模型}

\section{1 理论框架}

根据外部性理论,环境污染问题的解决, 从根本上讲是成本 与收益的比较,环境规制主要是通过影响生产过程的成本和资 源利用效率等因素对产业增长和技术水平产生影响 ${ }^{[11]}$. 当政府 对产业实施环境规制时,产业绩效既包括企业在一定市场结构 条件下市场行为的效果,也包括政府对市场组织与调节的效 果 ${ }^{[12]}$. 在技术状况和需求条件不变的情况下, 随着规制强度的 增加,企业的成本增加, 必然导致产出率的下降 (阻碍效 应 ${ }^{[34]}$; 同时,环境规制也可能对产业绩效产生促进效应,一方 面通过环境规制标准的实施,可以关闭污染高产能低的企业或 者提高新进企业的准人标准,从而以改变产业结构的途径提高 生产率;一方面可能对企业的创新活动产生激励作用,通过技术 进步提高产业绩效 ${ }^{[5-7]}$ (图 1). 环境规制对制造业产业绩效的最 终影响取决于两者的综合效果.

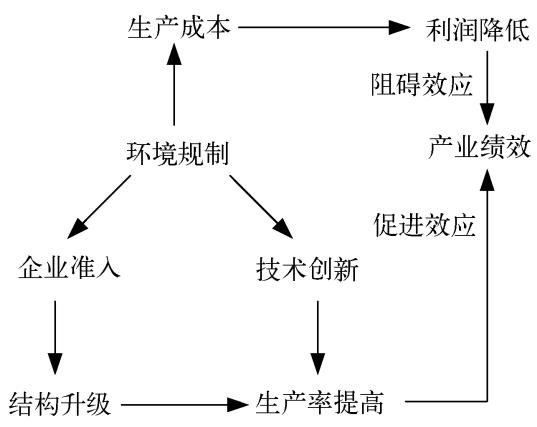

图 1 环境规制对产业绩效的影响机制

Fig. 1 Effects of environmental regulation on industrial performance

本文在现有理论分析的基础上,提出以下理论假设:环境规 制对制造业产业绩效的影响具有强度效应,即在需求条件不变以及其他因素不变的情况下,环境规制最终 能对产业绩效产生正向的促进或者逆向的阻碍作用, 取决于环境规制的强度大小. 规制强度与产业绩效之 间存在着一个突变点或临界点, 在临界点以下, 规制强度对企业进行技术创新的驱动力不足, 环境规制又要 求企业通过支付污染费用或者改变生产过程和生产工艺等手段减少排污,这就会导致生产成本增加以及产 出和利润的下降. 当环境规制强度在临界点以上时,环境规制的刺激能力开始成倍的增加,企业的准人壁垒 增加,同时开始引发技术创新从而导致经济增长方式和产业绩效的转变, 此时 “创新补偿” 作用开始显 现 ${ }^{[13]}$, 通过技术创新所产生的利润已经能够弥补污染治理的成本消耗, 从而使得产业达到经济效益和环境 效益同时改进的双赢状态.

因此,本文以无锡市为实证地区, 考察环境突发事件(水危机)前后环境规制强度的变化以及对制造业 产业绩效的影响,以期探讨环境规制对产业发展的影响机制.

\section{2 研究方法}

本文在对环境规制强度定量评估的基础上,分析环境规制对生产成本、企业准人、技术创新以及产业绩 效的影响, 同时分别构建环境规制与各要素之间的二元回归模型 ${ }^{[14]}$, 定量探讨其影响机制. 由于数据原因, 回归样本量不够, 同时解释变量之间存在着相关性, 即多重共线性问题. Blanchard 等认为, 当遇到数据有严 重的多重共线性时,可以采取 “无为而治” 的方法,即我们不能准确地估计多个回归系数,但可以相对有效地 分别估计一个线性组合 ${ }^{[14]}$.

1.2.1 环境规制强度的评估 环境规制强度主要表征政府规制政策对制造业增长方式转变和企业污染治理 行为的影响程度. 本文在对现有主要环境保护制度总结的基础上,借鉴丁文广对环境规制工具的分类体系， 构建了环境规制强度的评价指标体系，主要分为四类规制手段，即政府规制、技术规制、市场化规制以及社 会规制手段 ${ }^{[15]}$. 环境规制强度的评估首先是在对以上环境规制手段分类的基础上,利用层次分析法确定各 环境规制手段的指标权重 (表 1)，其中指标权重的确定主要考虑各类环境规制手段对于污染控制、产业结构 及其发展方式转变的作用力度和效果. 其次,运用德尔菲法确定具体环境政策手段的得分,根据历年所采用 的环境政策数量及其相对应的得分进行累加赋值. 
表 1 环境规制强度评价指标体系及相关权重

Tab. 1 The indicators and weights of environment pressure

\begin{tabular}{lll}
\hline 环境规制类型 & 权重 & 评分标准 \\
\hline 政府规制 & 0.3953 & 3 立法和法规 \\
& & $\begin{array}{l}\text { 规划、通知、办法和意见 } \\
1 \text { 运动和行政措施 }\end{array}$ \\
\hline 技术规制 & 0.1867 & 3 循环再生技术及信息化技术 \\
& & $\begin{array}{l}\text { 清洁生产技术 } \\
1 \text { 污染物末端处理技术 }\end{array}$ \\
\hline 市场化规制 & 0.2928 & 4 税收制度 \\
& 3 排污权交易制度 \\
& 2 信贷、补贴 \\
& 1 环境责任保险制度及其他 \\
\hline & & 3 绿色标志认证 \\
& 2 信息公开 \\
1 公民社会与环境 NGO
\end{tabular}

1) 政府规制手段是政府运用标准或 规定直接作用于控制对象的规制方式, 具 有针对性强、执行有效的特点, 对短期类 污染控制和产业调整具有十分重要的影 响, 因此赋以最高的权重. 其中, 立法和法 规具有强制性和最高约束力, 行为主体必 须承担相应的后果, 对产业转型发展的影 响程度最大, 规划、通知、办法和意见通常 是地方政府根据法规所指定的具体规章, 其影响稍次于立法, 而运动和行政措施是 根据以上立法和规章制度所采取的具体 手段,它取决于政府的执行力度和效率, 较以上两种方式具有一定的不确定性, 影 响相对较小.

2) 市场化规制手段主要是通过实施 资源有偿制度和运用价格杜杆对污染行 为进行规制, 但是, 由于我国正处在环保 市场机制探索阶段,市场化工具对环境污 染的控制还没有完全发挥其基础性的调 节作用,所以, 对其赋以次于政府工具的 权重. 各类具体手段对企业成本的影响以 及污染控制效果的不同,对区域产业发展

的影响程度也有差异, 其中税收制度是社会成本内部化, 因此对企业影响程度最大, 对污染控制最有效; 排 污权交易制度相对次之; 信贷和政府补贴可以在一定程度上增加企业采用环保技术的积极性,效力较小; 环 境责任保险制度相对来说取决于企业的环保意识和水平, 效力最小.

3) 环境技术规制是基于一定时期环境发展理念及环境管理体制而形成的,包括环境技术的引进和创 新、环境技术的选择、技术结构的调整和变革、环境产品结构在内并与之相关的各个方面的总和, 是达成环 境目标的必要手段. 无锡地区虽然经济发展水平发达, 但是制造业发展过程中以资源的大量消耗为主,在短 时间内, 技术对污染的控制效果总体来说较政府和市场化工具相对较小, 因此赋以较低的权重. 现阶段, 技 术工具主要分为循环再生技术及信息化技术、清洁生产技术和污染物末端处理技术, 根据其对污染治理的 有效性和持久性,分 3 个等级进行赋值.

4) 社会化规制手段主要是建立在企业、公众具有较高的环境意识基础上的,随着经济发展水平的提升, 政府部门加强环境保护的宣传教育, 企业、公众的环境保护意识会逐渐增强, 其对污染事件的环境压力也会 提升. 由于不具有强制性和经济刺激, 不确定性较强和见效最慢, 因此赋以最低的权重. 根据其包含的具体 指标对企业环境行为的相对约束性, 分别给绿色标志认证赋以最高得分, 企业信息公开次之, 公民社会与环 境 NGO 最低.

1.2.2 产业绩效的表征 全要素增长率 $(T F P)$ 是衡量产业绩效的重要指标, 指扣除资本投人和劳动投人贡 献以外其他所有能实现经济增长的因素总和,包括创造新技术、采用新的管理办法、制度的变迁、宏观政策 的变化以及市场环境的改变等 ${ }^{[16]}$. TFP 主要是通过建立在增长速度方程和生产函数基础上的索罗余值法对 全要素生产率进行测算, 理论模型 ${ }^{[17]}$ 为:

$$
G Y=\alpha G K+\beta G L+T F P G
$$

该式是指从经济增长率中减去固定资本存量和劳动力所解释的部分, 剩下的部分是对技术进步的估 计. 式中, $G Y$ 为经济增长率, $G K$ 为固定资本存量增长率, $G L$ 为劳动力增长率, $T F P G$ 为全要素生产率增长率, 如果 TFP $>1$, 表明产业绩效水平比上一年提高, 反之则表示比上一年退后. $\alpha$ 和 $\beta$ 分别为资本和劳动的产出 
弹性,具体计算过程是根据 Cobb-Douglas 生产函数,用最小二乘法进行估计,回归方程为:

$$
\ln Y_{t}=\ln A+\alpha \ln L_{t}+\beta \ln K_{t}+\mu_{t}
$$

式中, $Y_{t} 、 L_{t} 、 K_{t}$ 分别为第 $t$ 年的制造业产出、劳动投人及资本投人; $\alpha$ 和 $\beta$ 分别代表制造业劳动力投人、资本 投人的产出弹性; $\mu_{t}$ 为随机误差项.

利用 2001-2009 年无锡市制造业工业总产值 $(Y)$ 作为衡量产出的基本指标,并以 2000 年为基准的 GDP 平减指数进行折算, 单位为亿元; 劳动投人制造业年均从业人员 $(L)$ 度量, 单位为万人; 资本投人用制造 业物质资本存量 $(K)$ 度量, 单位为亿元, 采取永续盘存法度量制造业的物质资本存量,基本公式为:

$$
K_{t}=K_{t-1}(1-\delta)+I_{t}
$$

式中, $K_{t}$ 表示第 $t$ 年的资本存量, $K_{t-1}$ 表示第 $t-1$ 年的资本存量, $\delta$ 为资本折旧率, $I_{t}$ 为第 $t$ 年净投资量. 考虑到数据的可得性, 我们将 2000 年的制造业固定资产净值余额作为基年的资本存量, 当年净投资 $I_{t}$ 采用每年制造业的固定资产投资,并根据固定资产价格指数折算为 2000 年的价格,资本折旧率 $\delta$ 选 取 $17 \%{ }^{[18](1)}$.

1.2 .3 生产成本、企业准入、技术水平等变量表征 生产成本表征: 治理成本体现由于污染治理费用而导致 的生产成本增加对产业绩效的影响, 以污染源治理总额占制造业工业总产值的比例来直接表征环境规制对 生产成本的影响. 企业准人表征: 环境规制对制造业企业准人的影响主要是通过关闭已有重度污染型企业 和对新进企业的准人设置壁垒两种途径, 表现在宏观上即为产业结构的升级和优化, 即污染密集型企业 ${ }^{[19]}$ 的减少和非污染密集型企业的引人增加,所以本文以污染密集型行业生产总值占工业生产总值之比来表示 技术水平: R\&D 支出反映了企业在研究与开发上的投人,主要反映的创新活动与技术改造提升和污染治理 效果的关系 ${ }^{[20]}$,因此本文采用 R\&D 支出占财政支出的比例来表征技术水平.

\section{2 结果及讨论}

\section{1 环境规制措施及评价}

2.1 .1 水危机前后无锡市环境规制措施分析 2005 年开始,无锡市各级政府为了落实中央政府提出的“科 学发展观”, 就开始提出通过关闭“五小”、“三高两低”企业淘汰高能耗、高污染和低附加值的企业,启动企 业退城进园,引进技术含量高的新兴制造业企业等提升产业结构. 但由于需要关闭的企业多半是当地财税 的重要来源, 因此水危机之前各项关停工作受到基层干部和企业明里暗里的抵制而进展缓慢. 水危机爆发 后,在不到 1 个月时间就关掉了其中的 323 家,仅仅两年左右时间, 累计关停“五小”和“三高两低”企业 1607 家,基本完成三年目标任务. 同时企业退城进园进程加快,全年新增搬迁人园企业 394 家,拆迁园外企 业建筑面积 $161 \times 10^{4} \mathrm{~km}^{2}$,乡镇工业集中度达 $83 \%$. 水危机所导致的环境规制手段和强度的转变对无锡市 制造业发展的触动可见一斑 2 .

通过对无锡市相关部门的调研以及相关资料的整理,本文对 2001-2007 年的主要环境政策进行了定性 的总结 (表 2). 从具体环境政策内容可以看出,太湖水危机出现后,无锡市政府在水环境治理措施和手段方 面进行了一系列较为明显的转变.

一是环境规制政策从宏观规划到微观意见的转变,更加注重针对性和实施性. 在相关立法、规划、意见 及通知上,水危机之前较多的为宏观指导性的规划为主,而水危机之后的规划更加注重对对产业结构的调 整和落后产能淘汰的具体措施, 同时,在具体实施时,也将环境治理作为干部考核指标, 实施“一票否决”制, 从而强化了环境政策的实施.

(1) 制造业相关数据主要来自于 2000-2009 年的《无锡市统计年鉴》. 污染密集型制造业是文献 ${ }^{[19]}$ 中所列举 的污染密集型产业中属于制造业的产业总和，包括纺织业、食品制造业、造纸业、石油化工业、治金业; 非污染密集 型制造业为除去污染密集型制造业的其他制造业产业.

(2) 相关数据来源于无锡市经济与信息化委员会网站:http://etc. wuxi. gov. cn/. 
表 2 太湖水危机前后无锡市环境政策比较

Tab. 2 Comparation of environmental regulation policies before and after Lake Taihu Water Crisis

\begin{tabular}{|c|c|c|c|}
\hline 类型 & 指标 & 水危机前 (2001－2006 年) & 水危机后 (2007－2008 年) \\
\hline \multirow{9}{*}{$\begin{array}{l}\text { 政 } \\
\text { 府 } \\
\text { 工 } \\
\text { 具 }\end{array}$} & 立法和法规 & 2003 年: 江苏省水资源管理条例 & $\begin{array}{l}2008 \text { 年:《江苏省人民代表大会常务委员会关于 } \\
\text { 加强饮用水源地保护的决定》、《江苏省太湖水污 } \\
\text { 染防治条例 }-2008 》 、 《 \text { 无锡市水环境保护条例 } \\
2008 \text { 年修订》 }\end{array}$ \\
\hline & \multirow{4}{*}{$\begin{array}{l}\text { 规划、意见、办 } \\
\text { 法和通知 }\end{array}$} & $\begin{array}{l}2001 \text { 年: 《太湖水污染防治“十五”计 } \\
\text { 划》、《无锡市环境保护“十五”计划和 } \\
2010 \text { 年远景规划》、《关于加强化工企 } \\
\text { 业环保审批监督管理的意见》 }\end{array}$ & $\begin{array}{l}2007 \text { 年:《关于加强开发区环境专项整治工作的 } \\
\text { 意见》、《无锡市饮用水水源保护办法》 }\end{array}$ \\
\hline & & $\begin{array}{l}2002 \text { 年:《无锡市贡湖供水水源保护办 } \\
\text { 法》 }\end{array}$ & $\begin{array}{l}2008 \text { 年:《高起点规划高标准建设无锡太湖保护 } \\
\text { 区决定》《《无锡市产业结构调整指导目录》、《太 } \\
\text { 湖保护区建设三年行动纲要 }(2008-2010) 》 、 《 \text { 关 } \\
\text { 于开展太湖流域地区化工行业污染整治工作的通 } \\
\text { 知一 } 2008 》 \text { 《中共无锡市委、无锡市人民政府关于 } \\
\text { 深化完善“河长制” 管理工作的实施意见》 }\end{array}$ \\
\hline & & $\begin{array}{l}2005 \text { 年:《关于开展太湖流域地区化工 } \\
\text { 行业污染整治工作通知-2005》 }\end{array}$ & $\begin{array}{l}2009 \text { 年:《太湖流域水环境综合治理总体方案》、 } \\
\text { 《无锡市主要水污染物排放指标有偿使用收费管 } \\
\text { 理实施办法》 }\end{array}$ \\
\hline & & $\begin{array}{l}2006 \text { 年:《“三城同创”五年行动计划 } \\
(2006-2010 \text { 年)》、《无锡市生态市建 } \\
\text { 设规划》《《无锡市 “十一五” 循环经济 } \\
\text { 发展规划》 }\end{array}$ & $\begin{array}{l}2010 \text { 年:《市政府关于加快淘汰落后产能工作的 } \\
\text { 实施意见》、《无锡市环境污染责任保险实施意 } \\
\text { 见》 }\end{array}$ \\
\hline & \multirow{4}{*}{$\begin{array}{l}\text { 运动和行动 } \\
\text { 措施 }\end{array}$} & $\begin{array}{l}2001 \text { 年:建设项目的“三同时” 管理制 } \\
\text { 度、环境影响评价制度、环境保护工作 } \\
\text { 责任考核制度 }\end{array}$ & \multirow[t]{2}{*}{$\begin{array}{l}2007 \text { 年:治太保源 “6699”行动、环保优先 “八大” } \\
\text { 行动、“河长制” 和“片长制” 管理制度、环保飞行 } \\
\text { 检查制度 }\end{array}$} \\
\hline & & 2002 年: 污染集中控制制度 & \\
\hline & & $\begin{array}{l}2003 \text { 年: 清理整顿不法排污行为, 保障 } \\
\text { 群众健康环保行动 }\end{array}$ & $\begin{array}{l}2008 \text { 年:环境治理“一票否决”制、“六查一提高” } \\
\text { 环境联合执法监查制度 }\end{array}$ \\
\hline & & $\begin{array}{l}2006 \text { 年:关闭“五小”、“三高两低”企 } \\
\text { 业,启动企业退城进园 }\end{array}$ & 2010 年: “三城同创”环保治太 \\
\hline & 技术工具 & $\begin{array}{l}2001-2003 \text { 年:清洁生产审计 } \\
2004-2006 \text { 年:循环经济试点 }\end{array}$ & $\begin{array}{l}2008-2010 \text { 年:建立 “ } 7+1 \text { ”政产学研战略联盟、 } \\
\text { 循环再生技术、生态及信息化技术 }\end{array}$ \\
\hline & 市场工具 & 2002 年: 排污许可证制度 & $\begin{array}{l}2007 \text { 年:绿色信贷体系,补贴 } \\
2008 \text { 年:排污权有偿使用制度、区域环境生态补 } \\
\text { 偿机制 } \\
2009 \text { 年:水污染物排放总量指标有偿分配和交易 } \\
\text { 制度、环境污染责任保险制度 } \\
2010 \text { 年:能源合同管理制度 }\end{array}$ \\
\hline
\end{tabular}

2001 年: ISO14000 认证、企业环境行为 信息公开化制度、环境法制教育、环保

社会工具 110 建设、绿色创建

2005 年: 网站增设环保政策法规及环 境状况月报
2007 年:信息公开评定等级升降制度、“全民环保 行动”

2009 年: 百日环保法规宣传服务、环境保护和太 湖治理 “大督查机制”、成立环保审判庭和合议庭 
二是环境规制管理手段从被动遵从上级意见到地方政府主动创新转变. 在 2007 年太湖水危机的警钟 之后,地方政府实施了治太保源“6699”行动和环保优先 “八大”行动，展开了“治理太湖、保护水源、重建 生态”攻坚战，同时高起点、高标准建设太湖保护区，创造性的提出了“河长制” 和“片长制”、“六查一提 高”环境联合执法检查制度、“飞行检查制度”等,不仅有效的治理了当地的环境,而且在全国也开始逐渐 推广.

三是环保技术从主要以末端治理为主向以科技为支撑的全过程控制手段为主转变. 在水危机之前, 无 锡市虽然在部分有条件的企业开展了清洁生产试点,但主要的环保手段仍然以末端治理为主, 而在水危机 之后,当地政府在扩大清洁生产和循环经济的基础上,利用 “ $7+1$ ”政产学联盟,加强科研实力,通过引进国 外先进技术进行污染治理和改善企业生产流程,使无锡市污水处理水平处于国际领先的地位.

四是从单一行政控制向兼顾市场化工具多样化管理转变. 水危机之前, 无锡只是根据省里的要求, 进行 单一的排污许可证制度,而在水危机之后, 当地政府积极探索运用经济手段来激励企业减排的手段,建立了 排污权有偿使用和交易制度、环境污染责任保险制度、绿色信贷制度以及环境资源区域补偿制度等多样化 的市场化治理制度.

2.1 .2 无锡市环境规制强度变化分析 根据环 境规制强度定量评估方法, 对以上各年的环境 政策分类进行评估,最终得到历年环境规制强 度的综合得分 (图 2). 结果表明, 水危机事件 后, 环境规制强度显著增加, 均值在 $2007-$ 2009 年期间比 2001-2006 年增加了 1.9 倍, 说 明环境事件使得规制强度出现了突变,这与 Plummer 等学者对于危机事件演变机制模型的 研究也较为一致 ${ }^{[21]}$; 政府工具、技术工具、市场 工具以及社会工具的规制强度分别增加了 2.2 、 $1.0 、 2.6 、 0.7$ 倍,其中, 市场化工具的作用强度 增速最大,政府在加强行政管理的同时已经开 始积极探索市场化治理的工具; 从环境规制手 段的构成来看,水危机之后环境规制中以规章 制度、行政措施为主的政府规制手段占比仍然 较高,这表明以政府工具为主的规制模式仍然 没有改变,说明政府为了在短期内实现污染治 理和产业调整目标, 比较倾向于采取针对性强、 执行有效的强制性规制政策.

\section{2 制造业污染治理成本的变化分析}

虽然污染治理投资额逐渐增长, 但是其占 工业生产总值的比重却出现了较为明显的波动 性(图 3). 2001-2007 年期间, 污染治理投资 额的比重较为稳定, 有时还会呈现下降趋势, 这 表明此时相关的环境规制不仅没有对企业的生 产成本造成影响,而且地方政府可能为了追求

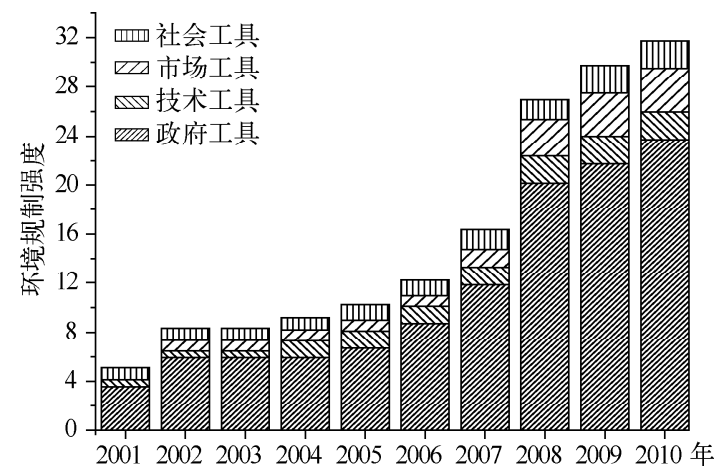

图 2 环境规制强度及其构成变化

Fig. 2 Strength and structure of environmental regulation

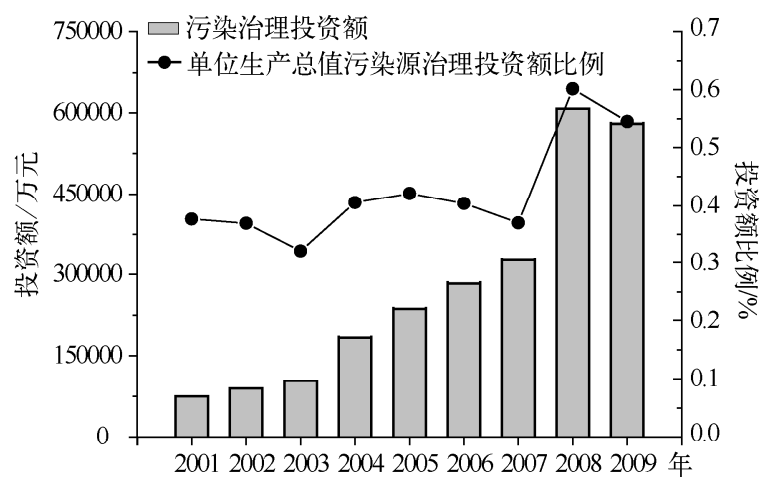

图 3 污染源治理投资额 (2001-2009 年)

Fig. 3 Pollution abatement investment (2001 - 2009)

经济增长而放松对相关企业的规制, 存在 “逐底” 效应 ${ }^{[22]}$; 2007 年开始环境治理成本有较大水平的提高, 2009 年比 2007 年增加了近 $20 \%$, 这表明政府出台的环境规制政策已经促使企业和相关部门开始主动进行 污染治理方面的投资.

\section{3 制造业行业构成的变化分析}

从行业结构来看 (图 4), 污染密集型制造业与非污染密集型制造业出现了较大的变动, 2001-2005 年 


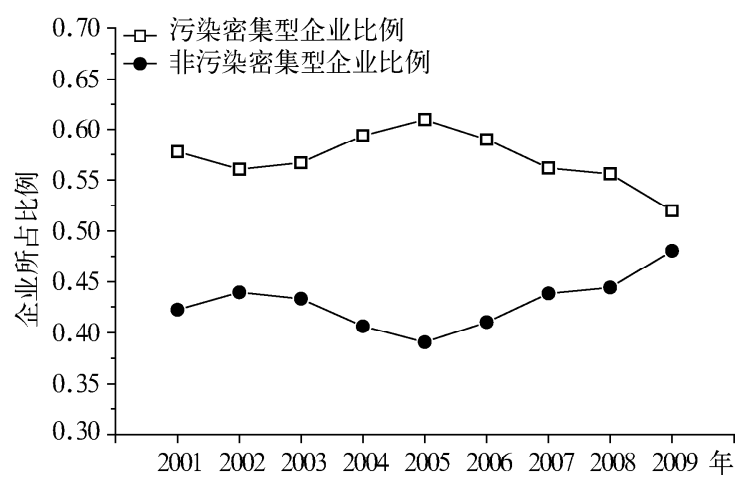

图 4 制造业产业结构变化(2001－2009 年)

Fig. 4 Restructuring of manufacturing industrial(2001-2009)

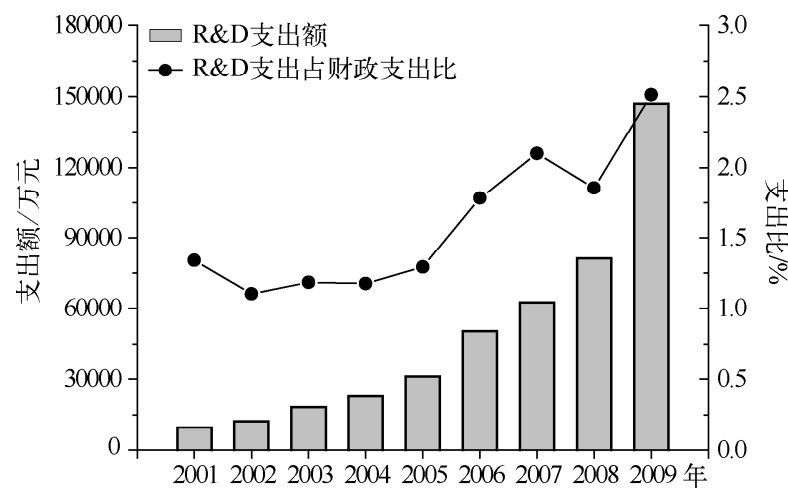

图 $5 \mathrm{R} \& D$ 经费支出变化情况 $(2001-2009$ 年)

Fig. 5 Changes in R\&D expenditure (2001-2009)

表 3 无锡市制造业各要素构成比较 $(2001-2009$ 年)

Tab. 3 Factors of production in manufacturing industries in Wuxi City (2001 - 2009)

\begin{tabular}{lrrrr}
\hline 年份 & $T F P$ & $\begin{array}{c}\text { TFP } \\
\text { 贡献率 }\end{array}$ & $\begin{array}{c}\text { 物质资本 } \\
\text { 贡献率 }\end{array}$ & $\begin{array}{r}\text { 劳动力 } \\
\text { 贡献率 }\end{array}$ \\
\hline 2009 & 1.47 & $37.98 \%$ & $53.80 \%$ & $8.22 \%$ \\
2008 & 1.32 & $42.45 \%$ & $58.86 \%$ & $-1.31 \%$ \\
2007 & 1.22 & $33.19 \%$ & $60.50 \%$ & $6.31 \%$ \\
2006 & 0.89 & $23.10 \%$ & $67.86 \%$ & $9.04 \%$ \\
2005 & 0.82 & $13.38 \%$ & $79.74 \%$ & $6.89 \%$ \\
2004 & 0.85 & $35.47 \%$ & $58.72 \%$ & $5.81 \%$ \\
2003 & 1.02 & $10.00 \%$ & $82.53 \%$ & $7.48 \%$ \\
2002 & 1.03 & $26.73 \%$ & $67.24 \%$ & $6.02 \%$ \\
2001 & 1.04 & $49.93 \%$ & $51.96 \%$ & $-1.89 \%$ \\
$2009-2007$ 均值 & 1.04 & $37.87 \%$ & $57.72 \%$ & $4.41 \%$ \\
$2004-2006$ 均值 & 0.86 & $23.98 \%$ & $68.77 \%$ & $7.25 \%$ \\
$2001-2003$ 均值 & 1.34 & $28.89 \%$ & $67.24 \%$ & $3.87 \%$ \\
\hline
\end{tabular}

之间,污染密集型制造业占到全部制造业生 产总值的 $60 \%$ 左右, 且有逐年上升的趋势, 此 时, 相关的环境规制还主要是针对污染的末 端治理; 而 2005 年以后, 由于针对制造业布 局调整意见的出台, 污染密集型制造业的比 重开始下降, 特别是水危机之后, 其下降趋势 更加明显, 至 2009 年, 非污染密集型制造业 所占比例与污染密集型制造业基本相同. 以 上结果表明,关闭“三高两低” “五小”企业、 退城进园等针对行业调整的环境规制政策已 经对产业结构优化升级产生了一定的倒逼 作用.

\section{4 制造业技术水平的变化分析}

随着财政收人的增加, 无锡市科研经费 支出的绝对额度呈现逐渐增长的态势, $R \& D$ 支出占财政收人的比重变化较为明显, 2001-2005年期间,一直处于较低水平, 只占 财政支出的 $1 \%$ 左右 (图 5 ). 而 2005 年以来, 在市委市政府的正确领导下, 无锡市加大了 科技创新的组织力度, 并于 2006 编制了《十 一五循环经济发展规划》, 引导和鼓励企业 加大研发投人, 提出努力从制造向创造迈进 的目标, 因此, 全市 $R \& D$ 支出占财政支出的 比例呈持续快速增长态势, 从 2005 年的 $1.29 \%$ 增加到 2009 年的 $2.51 \%$, 已经达到发 达国家水平. 这表明, 政府对制造业企业的技 术规制的效果较为明显.

\section{5 制造业产业绩效的变化分析}

全要素生产率经历了先下降后上升的趋 势 (表 3),2001－2003 年全要素生产率大于 1 , 表明此时产业绩效水平逐渐提高, 而 2004 - 2006 年期间不断下降, 处于产业绩效逐渐 降低阶段, 且全要素生产率对于经济增长的 贡献率也逐渐下降, 而 2007 年为拐点出现的 时间, 产业绩效开始明显提高, 全要素生产率 在此时对经济增长的贡献率持续增长, 平均 增长率为 $21.3 \%$, 这和吴敬琏等对于无锡生 产方式变化趋势的计算也基本相同 ${ }^{[23]}$. 结果 表明, 水危机之后, 无锡制造业增长方式已经 开始发生转变, 技术效率和水平对于经济增 长的贡献度显著增强. 但是, 通过各类要素对 制造业产值增长的贡献率来看, 虽然水危机 之后物质资本的贡献率有一定的下降, 即从 $79 \%$ 左右降低到了 $53.8 \%$, 但是要素的投人 
始终是生产增长的最主要因素,而技术和人力资本等效率提高还远远没有成为推动制造业发展的主要动 力. 相关研究表明中国城市的研发投人多数集中在某些新兴产业中,而对传统的制造行业则主要还是靠资 本和人力的投人,特别是自主创新的关键技术和核心技术相对缺乏, 因此对产业绩效的影响不明显 ${ }^{[24]}$.

\section{6 环境规制对制造业产业结构优化和绩效的影响机制分析}

环境规制与治理成本、企业准人、R\&D 支出以及产业绩效之间的二元回归模型计算结果如下: 治理成 本、R\&D 支出以及产业绩效的 $R^{2}$ 均大于 $0.7, F$ 值检验表明在 $1 \%$ 置信范围内显著,说明拟合效果较好,而 企业准人的拟合效果稍差. 从回归系数来看,环境规制对企业治理成本、R\&D 支出以及产业绩效都有显著的 促进作用,其中对产业绩效的影响最为显著;而环境规制对污染行业的准人也有显著的限制作用,表现为显 著负相关 (表 4$)$.

表 4 二元回归模型分析结果

Tab. 4 Results of regression model analysis

\begin{tabular}{crrrrrr}
\hline 变量 & 系数 & 标准差 & $t$ 值 & $R^{2}$ & $F$ 值 & 显著性 \\
\hline 治理成本 & 0.0092 & 0.0019 & 4.8392 & 0.7699 & 23.4179 & 0.0019 \\
企业准人 & -0.0021 & 0.0008 & -2.6648 & 0.5036 & 7.1012 & 0.0322 \\
R\&D 支出 & 0.0483 & 0.0112 & 4.3020 & 0.7256 & 18.5072 & 0.0036 \\
产业绩效 & 0.7711 & 0.0052 & 4.1283 & 0.7089 & 17.0430 & 0.0044 \\
\hline
\end{tabular}

回归结果表明,近年来特别是水危机之后,无锡市通过提高治理成本和科技支出,限制污染企业的准 人, 实现了产业结构的升级和生产绩效的提高, 抵消了环境规制对生产成本增加而产生的消极作用. $2001-$ 2006 年期间, 无锡制造业增长迅速, 人口快速积累,城市化进程加快, 然而高增长是以高投人和高污染为代 价, 经济增长方式未根本转变, 传统低附加值高污染行业如印染、造纸、化工、酿造等在工业中仍占较高比 重, 高附加值低污染的制造行业比重不高, 从而导致在 2001-2006 年间全要素生产率的贡献率不升反而明 显降低. 相反, 由于水危机事件而导致针对产业结构和发展转型的环境规制政策的出台,制造业整体的技术 效率和水平得到明显的提高. 在水危机事件暴发之后,地方政府在处理产业发展和环境之间矛盾上,坚持环 境优化发展战略,一方面,坚决淘汰落后产能、高污染低附加值的企业逐渐被“关、停、并、转”,污染密集型制 造业的结构日趋调整, 另一方面, 无锡市根据当地的资源承载力和环境容量, 实施区域差别化的环境准人制 度,在沿太湖、饮用水源地等环境敏感地区,重点发展 “低污染、低能耗、低物耗” 和 “高技术、高附加值、高市 场前景” 的高新技术产业和劳动密集型的传统工业,在环境相对不敏感地区,对高污染企业也实施了严格的 环境监管制度.

\section{3 小结}

本文通过构建环境规制强度的定量评价指标体系和制造业产业绩效的环境规制驱动模型, 对无锡地区 水危机事件前后的环境政策和制造业发展方式进行对比,研究了环境规制对制造业产业绩效的影响, 同时 对相应的机理进行了分析. 研究结果表明:

1) 水危机事件后,环境规制强度显著增加,政府、技术、市场及社会化工具的环境规制强度均值在 2007 -2009 年期间比 2001-2006 年期间分别增加了 2.2、1.0、2.6、0.7 倍, 可以看出, 政府在加强行政管理的同 时开始积极探索市场化治理的工具,但以政府规制为主的治理模式仍然没有改变.

2 ) 通过对影响产业绩效各要素的分析得出,2007 年水危机事件对污染治理投人、R\&D 支出、产业结构 的调整等都有显著的影响,污染密集型行业比重从 61\%下降到 52\%,产业绩效在此期间也有显著的提高,全 要素生产率对经济增长的贡献率达到 $40 \%$.

3 ) 回归结果进一步得出,环境规制通过影响企业准人和提高技术效率,实现了产业结构的升级和生产 效率的提高, 抵消了环境规制对生产成本增加而产生的消极作用,但是创新仍没有成为产业绩效增加的最 主要动力.

本研究不仅对探讨经济和环境可持续发展模式具有重要的理论指导意义,而且对于环境政策的合理制 
定具有一定的借鉴意义. 无锡市在水危机之后采取的各项环境政策对制造业发展方式的转变和污染控制已 经产生了较为显著的作用, 但是, 污染控制仍然以政府强制措施为主以及制造业发展仍然处在产业链较为 低端的局势并没有改变. 因此,一方面, 除了通过调整产业结构、加强企业的关停并转等遏制环境进一步恶 化的政策外,无锡市还要加大对制造业企业排污的市场化监管与治理,在现有的环保新政基础上,可以将水 污染物排污权交易制度扩展到其他污染物的排放上, 也可进一步考虑利用征收环境税等措施来提高环境治 理的效率;另一方面,无锡市有必要通过加大政府财政补贴和绿色信贷等方式,在政策导向上鼓励和扶持传 统低端制造业进行技术改造.

\section{4 参考文献}

[1] 林泽新. 太湖流域水环境变化及缘由分析. 湖泊科学, 2002, 14(2): 111-116.

[2] 周 燕, 朱晓东, 尹荣尧等. 太湖流域水环境长效管理研究. 环境保护科学, 2010, 36(3) : 84-95.

[ 3 ] Christainsen GB, Haveman RH. Public regulations and the slowdown in productivity growth. American Economic Review Proceedings, 1981, 71 : 320-325.

[ 4 ] Gray WB, Shadbegian RJ. Plant vintage, technology, and environmental regulation. NCEE working paper, 2001: 1-32.

[ 5 ] Porter ME, Linder CVD. Toward a new conception of the environment-Competitiveness relationship. Journal of Economic Perspectives, 1995, 9(4): 97-118.

[ 6 ] Hamamoto M. Environmental regulation and the productivity of Japanese manufacturing industries. Resource and Energy Economics, 2006, 28 (4) : 299-312.

[ 7 ] Kronvang B, Andersen HE, Borgesen C et al. Effects of policy measures implemented in Denmark on nitrogen pollution of the aquatic environment. Environmental Science and Policy, 2008, 11(2):144-152.

[8] 许冬兰, 董 博. 环境规制对技术效率和生产力损失的影响分析. 中国人口、资源与环境, 2009, 19(6): 91-96.

[ 9 ] Boyd GA, McClelland JD. The impact of environmental constraints on productivity improvement in integrated paper plants. Journal of Environmental Economics and Management, 1999, 38(2) : 121-142.

[10］解 严. 环境规制与中国工业生产率增长. 产业经济研究, 2008, (1): 19-26.

[11] Square R. Exploring the relationship between environmental regulation and competitiveness-A literature review. Working Paper, 2005, 6: 7-8.

[12] 杨公仆, 夏大慰, 龚仰军. 产业经济学教程. 上海:上海财经大学出版社, 2009: 89-91.

[13] Stavins RN. Market-based environmental policies. Washington, DC: Public Policies for Environmental Protection, 2007: 159-173.

[14] 达摩达尔 $\cdot \mathrm{N}$ - 古扎拉蒂. 计量经济学基础:上册. 北京: 中国人民大学出版社, 1996: 338-339.

[15] 丁文广. 环境政策与分析. 北京: 北京大学出版社, 2008: 54 .

[16] 杨晓光, 㷊 洁, 赵燕霞. 20 世纪 90 年代中国区域经济增长的要素分析. 地理学报, 2002, 57 (6) : 701-708.

[17] Solow R. Technical change and the aggregate production function. Review of Economics and Statistics, 1957, 39: 312-320.

［18］黄勇峰, 任若恩, 刘 晓. 中国制造业资本存量永续盘存法估计. 经济学, 2002, (2): 377-396.

[19］夏友富. 外商投资中国污染密集产业现状、后果及其对策研究. 管理世界, 1999, 14(3): 109-123.

[20] Czarnitzki D, Toole AA. Patent protection, market uncertainty, and R\&D Investment. The Review of Economic and Statistics, 2011, 93(1): 147-159.

[21 ] Plummer R, Velaniskis J, Crosbois D et al. The development of new environmental policies and processes in response to a crisis : the case of the multiple barrier approach for safe drinking water. Environmental Science and Policy, 2010, 13 : 535 548 .

[22] 刘卫东, 刘红光, 唐志鹏等. 出口对中国区域经济增长和产业结构转型的影响分析. 地理学报, 2010, 65(4): $407-415$.

[23] 吴敬琖, 黄少卿. 无锡经验一中国经济发展转型的个案研究. 上海: 远东出版社, 2010: 45-47.

[24] Jefferson GH, Bai HM, Guan XJ et al. R\&D performance in Chinese industry. Economics of Innovation and New Technolo$g y, 2006,15(5): 345-366$. 